\title{
Sister chromatid exchange evaluation as an aid to the diagnosis and exclusion of Fanconi's anaemia by induced chromosome damage analysis
}

\author{
R T Howell
}

\begin{abstract}
Evaluation of chromatid aberrations induced in culture by DNA cross linking agents provides the most reliable method currently available for the diagnosis and exclusion of Fanconi's anaemia. However, at appropriate concentrations of clastogenic agent the aberration frequency in an unaffected subject may be very low and thus it may be difficult to confirm that the treatment was effective.

Data are presented to show that sister chromatid exchange analysis can be used to monitor the effectiveness of the clastogen treatment and thereby increase the reliability and efficiency of the assay.
\end{abstract}

Fanconi's anaemia (FA), a rare syndrome with an autosomal recessive mode of inheritance, is associated with hypoplasia of the bone marrow, characteristically resulting in anaemia, neutropenia, and thrombocytopenia. ${ }^{1}$ There is a predisposition to malignancy, and the majority of patients die in the second or third decade as a result of bone marrow failure or malignant disease. ${ }^{2}$ In a proportion of patients, a variety of congenital defects, for example, hypoplasia of the radius and thumb, growth retardation, hypogonadism, hyperpigmentation, and cardiac and renal anomalies, may also be observed. However, it is now recognised that the expression of such abnormalities is so variable that diagnosis on the basis of clinical manifestations is unreliable. ${ }^{34}$

The genetic defect in FA is not known but deficiency of an enzyme responsible for some aspect of DNA management, possibly DNA repair, is suspected. This suspicion was initially based on the observation that the chromosomes of cultured cells display a raised level of instability manifesting as chromatid

South Western Regional Cytogenetics Centre, Southmead Hospital, Bristol BS10 5NB.

R T Howell

Received for publication 1 August 1990

Revised version accepted for publication 29 November 1990. type aberrations. ${ }^{5}$ Further, it became clear that the chromosomes show a remarkable hypersensitivity to the clastogenic effects of DNA cross linking agents, such as mitomycin $\mathrm{C}^{6}{ }^{6}$ nitrogen mustard, ${ }^{7}$ and diepoxybutane. ${ }^{8}$ This distinctive cytogenetic characteristic can be shown in a wide variety of cultured tissues and is accepted as a reliable means of confirmation or exclusion of FA, prenatally as well as postnatally, ${ }^{8-10}$ direct comparison of aberration yields being made with normal control cultures treated and analysed in parallel.

Spontaneous sister chromatid exchange (SCE) frequencies are believed to be normal in FA subjects, ${ }^{11}$ but studies on induced SCE have yielded conflicting results. Some reports indicate a reduced response to clastogenic stress, but in others normal or raised frequencies have been observed. Dallapiccola and Porfiro, ${ }^{12}$ in summarising these results, suggested that the inconsistencies might be a consequence of different treatment and culturing schedules, and that genetic heterogeneity of FA might also be a factor.

Confirmation and exclusion of FA by the evaluation of induced chromosomal aberration frequencies in cultured lymphocytes is now undertaken in many clinical cytogenetics laboratories, and in the great majority of cases a normal result is obtained. Clinical referral is sometimes made at birth, where an infant has, for example, radial aplasia or unexplained anaemia. Referrals later in childhood generally result from the observation of haematological problems, either coupled with some other clinical manifestations, or occurring in sibs.

After a positive diagnosis it is usual to perform the same laboratory tests on apparently unaffected sibs, specifically to exclude FA, in particular if a sib is to be considered as a possible bone marrow transplant donor.

Despite the clinical heterogeneity of the disease, the clastogen stress test is generally dependable. Problems of interpretation undoubtedly occur, however, ${ }^{4}$ and there are four easily identified potential problems.

(1) The test is performed only infrequently in many laboratories where routine reliable protocols may not be properly established. It is difficult for many 
laboratories to build up experience and maintain consistent standards for dealing with these referrals.

(2) At appropriate concentrations of the clastogenic agent, aberration frequencies in unaffected subjects may be extremely low and thus it may be difficult to confirm that the treatment was effective. In other words, it may be necessary to draw a conclusion from a negative response.

(3) Significant differences in aberration yields between cultures from different persons may be a consequence of different growth rates. Susceptibility to clastogenic agents varies widely depending on the stage of cell cycle, sensitivity in $S$ often being much higher than in $G_{1}$. Also, a greater yield of aberrations is to be expected at the first metaphase after exposure, except in $G_{2}$ cells which display high sensitivity at the second metaphase after exposure. ${ }^{13}$ (4) Treatment regimens may give inconsistent results over a period of time because of variations in batches of media and reagents. This may be of particular significance in laboratories undertaking the test on an occasional basis.

Incorporation of SCE evaluation into a clastogen stress test for FA can effectively reduce ambiguities and interpretive problems by providing a sensitive positive control, a significant rise in SCE frequency occurring in normal cells at concentrations of cross linking agents which induce only occasional aberrations. ${ }^{14}$ The results presented in this report show this method to be reliable in providing a diagnostic test for FA without the necessity for laborious and costly screening of aberrations in large numbers of cells.

\section{Methods}

A variety of clastogen treatments involving continuous exposure or pulse treatments applied at a variety of times during the culture period have been described, all giving satisfactory results in the majority of cases. $^{3} 7815$ The standard method for the blood samples dealt with in this report was to use three cultures from the patient with three parallel control cultures matched for sex and age if possible. Whole blood cultures were grown in McCoy's 5a medium supplemented with $10 \%$ fetal calf serum, PHA, and $10^{-5} \mathrm{~mol} / 15^{\prime}$ bromodeoxyuridine (BrdU), all cultures being harvested after three days' incubation. A pair of cultures (one patient and one control) was given a pulse treatment of $3 \times 10^{-6} \mathrm{~mol} / 1$ mitomycin C (MMC, Sigma) for approximately $\mathbf{4 0}$ minutes before culturing; $0.4 \mathrm{ml}$ of whole blood was suspended in $2.0 \mathrm{ml}$ of phosphate buffered saline (PBS) for exposure to MMC. After treatment, the suspension was centrifuged and resuspended in three changes of $10 \mathrm{ml}$ of PBS before adding the cells to the culture medium. A second pair of cultures was exposed to $10^{-7} \mathrm{~mol} / \mathrm{l}$ nitrogen mustard (HN2, mustine hydrochloride,
Boots) added 24 hours before harvesting. The third pair of cultures had no clastogen exposure.

In the standard analysis, 20 cells are scored for aberrations from the clastogen treated cultures, and SCE counted in up to five cells from all six cultures. Provided that a significant SCE response can be shown in the absence of a significant yield of aberrations in the patient's cultures, it is possible to exclude FA without examining the control cultures. For aberration analysis, slides were block stained in $10 \%$ Leishman's stain at pH 6.8 and for SCE by staining in Giemsa at $\mathrm{pH} 10 \cdot 4 .^{16}$

\section{Results}

SCE AND ABERRATION YIELDS IN PATIENTS IN WHOM FA WAS EXCLUDED

Data have been selected from five cases analysed recently to illustrate the typical pattern of results when FA is excluded. Table 1 shows high frequencies of SCE obtained from MMC and HN2 exposures, confirming that the treatments were effective. The differences in SCE levels between similarly treated cultures, especially observed after $\mathrm{HN} 2$ exposure, may reflect differences in growth kinetics between cultures of different subjects as well as variation in conditions on different occasions. However, as only small numbers of cells were examined some random discrepancy may be expected. Table 1 also illustrates the low aberration frequencies in all of these cultures.

\section{SCE AND ABERRATION YIELDS IN CONFIRMED FA PATIENTS}

Cases 1 and 2 were brothers aged 8 and 5 years referred because of thrombocytopenia, together with

Table 1 Combined data from five patients in whom $F A$ was excluded and five control samples showing spontaneous and induced SCE frequencies and induced aberrations. Five cells were scored per culture for SCE and 20 per culture for aberrations. The majority of aberrations were chromatid type. Details of the treatment protocols are given in the methods section.

\begin{tabular}{llll}
\hline & \multicolumn{3}{c}{ Treatment } \\
\cline { 2 - 4 } & None & \multicolumn{1}{c}{ MMC } & HN2 \\
\hline $\begin{array}{l}\text { SCE } \\
\begin{array}{l}\text { Overall mean } \\
\text { Range of } \\
\text { culture means }\end{array}\end{array}$ & $5 \cdot 7$ & $30 \cdot 1$ & $38 \cdot 0$ \\
$\begin{array}{l}\text { No of cells } \\
\text { Total aberrations }\end{array}$ & $3 \cdot 6-7 \cdot 6$ & $23 \cdot 2-37 \cdot 0$ & $21 \cdot 5-61 \cdot 2$ \\
$\quad$ Gaps & 50 & 50 & 50 \\
$\begin{array}{l}\text { Breaks cells } \\
\text { No of cells }\end{array}$ & & \\
$\begin{array}{l}\text { Aberrations per culture } \\
\text { (20 cells each) }\end{array}$ & 46 & 26 \\
$\begin{array}{l}\text { Mean } \\
\text { Range }\end{array}$ & 19 & 28 \\
\hline
\end{tabular}


Table 2 Induced SCE and aberration yields in FA patients and controls. Each block of cultures was grown and treated in parallel. Cases 1, 2, and 3 were affected, and the normal sib is the brother of cases 1 and 2 (see methods section for details of treatment protocols). At least 10 cells were scored for SCE except where indicated by*. Twenty cells were scored for aberrations in every clastogen treated culture.

\begin{tabular}{|c|c|c|c|c|c|}
\hline \multirow[b]{2}{*}{ Treatment } & \multirow[b]{2}{*}{ Patient } & \multirow[b]{2}{*}{ SCE per cell } & \multicolumn{3}{|c|}{ Aberrations per 20 cells } \\
\hline & & & Gaps & Breaks & Exchanges \\
\hline None & $\begin{array}{l}\text { Case } 1 \text { (FA) } \\
\text { Case } 2 \text { (FA) } \\
\text { Normal sib } \\
\text { Control }\end{array}$ & $\begin{array}{l}5 \cdot 4 \\
7 \cdot 7 \\
7 \cdot 7 \\
7 \cdot 7\end{array}$ & & & \\
\hline MMC & $\begin{array}{l}\text { Case } 1 \text { (FA) } \\
\text { Case } 2 \text { (FA) } \\
\text { Normal sib } \\
\text { Control }\end{array}$ & $\begin{array}{l}49 \cdot 5^{*} \\
42 \cdot 1 \\
49 \cdot 7 \\
61 \cdot 5\end{array}$ & $\begin{array}{r}19 \\
22 \\
2 \\
2\end{array}$ & $\begin{array}{r}38 \\
38 \\
3 \\
6\end{array}$ & $\begin{array}{r}37 \\
54 \\
1 \\
1\end{array}$ \\
\hline HN2 & $\begin{array}{l}\text { Case } 1 \text { (FA) } \\
\text { Case } 2 \text { (FA) } \\
\text { Normal sib } \\
\text { Control }\end{array}$ & $\begin{array}{l}38 \cdot 8 \\
40 \cdot 0 \\
38 \cdot 0 \\
31 \cdot 1\end{array}$ & $\begin{array}{r}8 \\
13 \\
2 \\
2\end{array}$ & $\begin{array}{r}22 \\
24 \\
1 \\
3\end{array}$ & $\begin{array}{r}17 \\
35 \\
0 \\
1\end{array}$ \\
\hline None & $\begin{array}{l}\text { Case } 3 \text { (FA) } \\
\text { Control }\end{array}$ & $\begin{array}{l}4 \cdot 0 \\
5 \cdot 2\end{array}$ & & & \\
\hline MMC & $\begin{array}{l}\text { Case } 3(\mathrm{FA}) \\
\text { Control }\end{array}$ & $\begin{array}{l}20 \cdot 0^{*} \\
19 \cdot 3\end{array}$ & $\begin{array}{l}6 \\
1\end{array}$ & $\begin{array}{r}29 \\
3\end{array}$ & $\begin{array}{r}21 \\
0\end{array}$ \\
\hline HN2 & $\begin{array}{l}\text { Case } 3 \text { (FA) } \\
\text { Control }\end{array}$ & $\begin{array}{l}15 \cdot 2^{*} \\
28 \cdot 0^{*}\end{array}$ & 2 & $\begin{array}{r}11 \\
2\end{array}$ & $\begin{array}{r}19 \\
0\end{array}$ \\
\hline
\end{tabular}

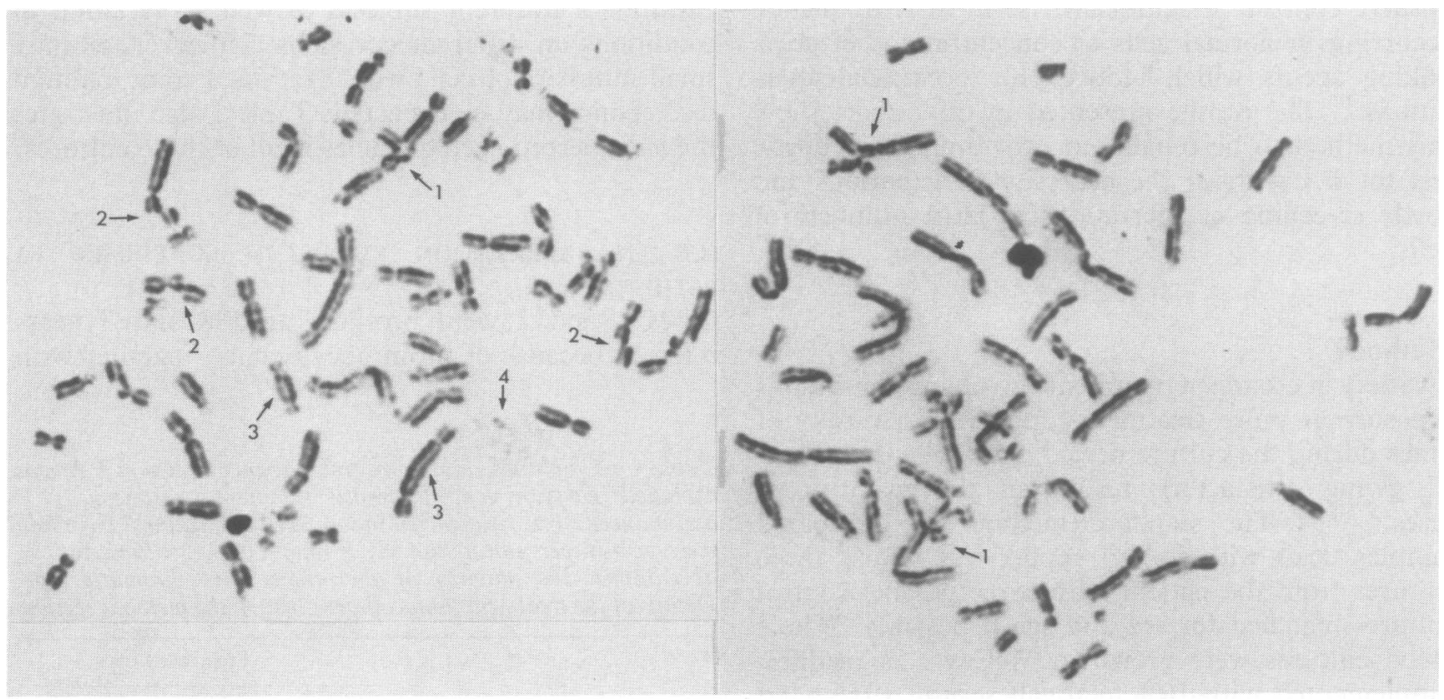

Harlequin staining in second division clastogen treated cells from a Fanconi's anaemia patient. (Left) $G_{0} M M C$ exposure showing a chromatid interchange (1), chromatid breaks (2), and derived first cycle damage in the form of dicentrics (3), and PCC (4). There are approximately 20 SCE. (Right) HN2 exposure for the final 24 hours, showing chromatid interchanges (1), and approximately $25 S C E$.

a normal sib being considered as a bone marrow transplant donor. Case 3 was a newborn presenting with radial aplasia. In all treated cultures from the three FA patients the aberration yields were extremely high (table 2). In the same cultures SCE frequencies were significantly raised with respect to the untreated cultures. SCE were difficult to score accurately in the presence of high levels of damage (figure). Following $\mathrm{G}_{0} \mathrm{MMC}$ exposure, few second division cells were found after 72 hours, probably because cells sustaining heavy chromosomal damage are unlikely to survive beyond their first post-treatment division. 
With the later mutagen exposure ( $\mathrm{HN} 2$ at 48 hours) more second divisions were available, many cells having already traversed one cycle before treatment.

\section{Discussion}

The results presented show that raised SCE levels may be used as a positive control in clastogen stress tests designed for the exclusion of Fanconi's anaemia. Confidence in the assay can be increased to a point where in many cases it becomes unnecessary to score aberrations in paired normal control cultures. Thus, exclusion can be made confidently, rapidly, and economically having examined relatively small numbers of cells. The tests can be undertaken on blood samples of 1 or $2 \mathrm{ml}$, an important consideration when investigations are carried out on neonates. This approach to the exclusion of FA is also facilitated by the use of a simple, five minute, harlequin staining technique using Giemsa stain at high $\mathrm{pH} .{ }^{16}$

SCE response to diepoxybutane (DEB) stress is similar to that found with $M M C$ or $\mathrm{HN}^{14}$ and protocols using DEB could be readily adapted to incorporate SCE evaluation.

Aberration yields in parallel clastogen treated cultures from different normal persons may not be fully comparable because of variability in growth rates. Comparisons between cultures from controls and affected patients may also be complicated by cell cycle differences, an elongated cell cycle, in particular an abnormally long $\mathrm{G}_{2}$ phase, being an established feature of FA cells. ${ }^{17} 18$ Such factors may have contributed to the false positive and false negative results obtained by some investigators. ${ }^{4}$ Harlequin staining provides the opportunity to compare the cell cycle of different cultures and the ability to confine the aberration analysis to first division cells if required. ${ }^{19}$

Data from observations of SCE levels in normal amniotic fluid or chorionic cultures might be used as an initial step in the development of suitable treatment protocols for the prenatal diagnosis of FA, and with the increasing use of bone marrow transplantation in the treatment of FA, the collection of data on induced SCE levels, in conjunction with aberration data, could be valuable for the long term monitoring of post-transplant cellular response to clastogenic agents.

Accurate diagnosis of Fanconi's anaemia is vital for appropriate patient management, and induced chromosome aberration analysis currently provides the most reliable means of confirming this condition. Incorporation of a modest load of SCE analysis is more than offset by the reduction in the amount of aberration screening required, enhancing confidence in the accuracy of the result and increasing further the efficiency of this assay.

The author wishes to thank Dr Alan McDermott for his advice in the preparation of this manuscript.

1 Salmon MA. Developmental defects and syndromes. Aylesbury: HM and M Publishers, 1978:211-2.

2 Swift M. Fanconi's anaemia in the genetics of neoplasia. Nature 1971;230:370-3.

3 Duckworth-Rysiecki G, Hultén M, Mann J, Taylor AMR. Clinical and cytogenetic diversity in Fanconi's anaemia. $\mathcal{f}$ Med Genet 1984;21:197-203.

4 Auerbach AD, Rogatko A, Schroeder-Kurth TM. International Fanconi anemia registry: relation of clinical symptoms to diepoxybutane sensitivity. Blood 1989;73:391-6.

5 Bloom GE, Warner S, Gerald PS, Diamond LK. Chromosome abnormalities in constitutional aplastic anaemia. $N$ Engl $\mathcal{F} M e d$ 1966;274:8-14.

6 Sasaki MS, Tonomura S. A high susceptibility of Fanconi's anaemia to chromosome breakage by DNA cross-linking agents. Cancer Res 1973;33:1829-36.

7 Berger R, Bernheim A, Le Coniat M, Vecchione D, Schaison G. Nitrogen mustard-induced chromosome breakage: a tool for Fanconi's anaemia diagnosis. Cancer Genet Cytogenet 1980;2: $269-74$

8 Auerbach AD, Adler B, Chaganti RSK. Prenatal and postnatal diagnosis and carrier detection of Fanconi anaemia by a cytogenetic method. Pediatrics 1981;67:128-35.

9 Auerbach AD, Zhang Min, Ghosh R, Pergament E, Verlinsky Y, Nicolas $\mathrm{H}$. Clastogen-induced chromosomal breakage as a marker for first trimester prenatal diagnosis of Fanconi anemia. Hum Genet 1986;73:86-8.

10 Shipley J, Rodeck CH, Garrett C, Galbraith J, Giannelli F. Mitomycin $\mathrm{C}$ induced chromosome damage in fetal blood cultures and prenatal diagnosis of Fanconi's anaemia. Prenat Diagn 1984;4:217-21.

11 Latt SA, Stetten G, Juergens LA, Buchanan GR, Gerald PS. Induction by alkylating agents of sister chromatid exchanges and chromatid breaks in Fanconi's anemia. Proc Natl Acad Sci USA 1975;72:4066-77.

12 Dallapiccola B, Porfiro B. Chromosomal studies in Fanconi anemia heterozygotes. In: Schroeder-Kurth TM, Auerbach $\mathrm{AD}$, Obe G, ed. Fanconi anemia, clinical, cytogenetic and experimental aspects. Berlin: Springer-Verlag, 1989:145-58.

13 Evans HJ. Molecular mechanisms in the induction of chromosome aberrations. In: Scott D, Bridges BA, Sobels FH. Progress in genetic toxicology. Amsterdam: Elsevier, 1977:57-74.

14 Perry P, Evans HJ. Cytological detection of mutagen-carcinogen exposure by sister chromatid exchange. Nature 1975;258:121-5.

15 Harrison CJ. Diagnosis of malignancy from chromosome preparations. In: Rooney D, Czepulkowski B, eds. Human cytogenetics: a practical approach. Oxford: IRL Press, 1986: 141-2.

16 Aghamohammadi SZ, Savage JRK. Reverse harlequin staining for late replicating chromosome bands and regions. Clin Cytogenet Bull 1989;2:62-3.

17 Dutrillaux B, Aurias A, Dutrillaux A, Buriot D, Prieur M. The cell cycle of lymphocytes in Fanconi's anaemia. Hum Genet 1982;62:327-32.

18 Hoehn H, Kubbies M, Schindler D, Poot M, Rabinovitch PS. BrdU-Hoechst flow cytometry links the cell kinetic defect of Fanconi anemia to oxygen hypersensitivity. In: SchroederKurth TM, Auerbach AD, Obe G, eds. Fanconi anemia, clinical, cytogenetic and experimental aspects. Berlin: SpringerVerlag, 1989:161-73.

19 Scott D. Homogeneous sensitivity of human peripheral blood lymphocytes to radiation-induced chromosome damage. Nature 1979;278:756-8. 